\section{ORIGINAL RESEARCH}

\section{E.G. Klompenhouwer \\ J.T.A. Dings}

R.J. van Oostenbrugge

S. Oei

J.T. Wilmink

W.H. van Zwam

\title{
Single-Center Experience of Surgical and Endovascular Treatment of Ruptured Intracranial Aneurysms
}

BACKGROUND AND PURPOSE: ISAT provided valuable data on patient outcome after endovascular coiling and surgical clipping of ruptured aneurysms. The purpose of this study was to retrospectively review the $\geq 1$-year outcome (in terms of survival, independence, and rebleeding) of patients who were treated in a routine clinical setting.

MATERIALS AND METHODS: Records of patients presenting with an SAH from a ruptured aneurysm between 2000 and 2008 were reviewed. The 403 patients who met the inclusion criteria harbored 443 treated aneurysms; 173 were managed surgically and 230 by endovascular means. Mean clinical follow-up was 33.9 months (range, 12-106 months).

RESULTS: The pretreatment clinical condition according to the $\mathrm{HH}$ was significantly better in the surgically treated patients $(P=.018)$. Death occurred in $11.6 \%$ after surgery and in $17.4 \%$ after endovascular treatment $(P=.104)$. Of the surviving patients in the surgical and endovascular groups, $80.3 \%$ and $87.2 \%$, respectively, were able to live independently with grades $0-2$ on the mRS $(P=$ .084). Complete aneurysm occlusion was achieved significantly more often after surgical treatment $(P<.001)$. Rebleeding occurred in $3.1 \%$ and $2.3 \%$ of the patients after surgical treatment and endovascular coiling, respectively. The occurrence of a residual aneurysm at the end of a coiling procedure was significantly related to the frequency of rebleeding $(P=.007)$.

CONCLUSIONS: The management of patients with intracranial aneurysms in a routine clinical setting shows good and comparable rates of mortality and independence. Coiling results in lower rates of complete aneurysm occlusion. Postcoiling angiography showing a residual aneurysm is a good predictor of the risk of rebleeding.

\begin{abstract}
ABBREVIATIONS: $\mathrm{ACA}=$ anterior cerebral artery; $\mathrm{ACA} \mathrm{A} 1=$ anterior cerebral artery proximal to the origin of the anterior communicating artery; $\mathrm{ACA} A 2$ = anterior cerebral artery distal to the origin of the anterior communicating artery; AcomA = anterior communicating artery; CTA $=\mathrm{CT}$ angiography; $\mathrm{DSA}=$ digital subtraction angiography; $\mathrm{GDC}=$ Guglielmi detachable coil; ICA = internal carotid artery; $\mathrm{HH}=$ Hunt and Hess scale; ISAT = International Subarachnoid Aneurysm Trial; MCA = middle cerebral artery; MCA M1 = middle cerebral artery proximal to the bifurcation; MCA M2 = middle cerebral artery distal to the bifurcation; MRA $=$ MR angiography; $m R S=$ modified Rankin scale; $\mathrm{PCA}=$ posterior cerebral artery; PcomA = posterior communication artery; $\mathrm{PICA}=$ posterior inferior cerebellar artery; SAH = subarachnoid hemorrhage; SCA = superior cerebellar artery
\end{abstract}

I ntracranial aneurysms are an important health problem worldwide, affecting about $2 \%$ of the population. ${ }^{1}$ Treatment consists of the exclusion of the malformation from the intracranial circulation to eliminate the risk of bleeding or rebleeding. Intracranial aneurysms can be treated by endovascular coiling or by surgical clipping. Since the introduction of GDCs, ${ }^{1,2}$ endovascular treatment of intracranial aneurysms has evolved rapidly as an alternative to microsurgical clipping. Coiling has become the preferential treatment since the ISAT demonstrated its clinical superiority over clipping in patients with a ruptured aneurysm who were eligible for both treatments. ${ }^{3-6}$ However, many patients are preferentially treated by either neurosurgery (eg, MCA aneurysms) or by endovascular treatment (eg, posterior circulation aneurysms). ${ }^{7}$ Moreover, coiling achieves lower rates of complete

Received March 30, 2010; accepted after revision July 30.

From the Departments of Radiology (E.G.K., S.O., J.T.W., W.H.v.Z.), Neurosurgery (J.T.A.D.), Neurology (R.J.v.O.), and Cardiovascular Research Institute Maastricht (R.J.v.O.), Maastricht University Medical Center, Maastricht, the Netherlands.

Please address correspondence to: Wim H. van Zwam, Department of Radiology, Maastricht University Medical Center, Mailbox 5800, 6229 HX Maastricht, the Netherlands; e-mail: w.van.zwam@mumc.nl

DOI 10.3174/ajnr.A2326 occlusion compared with microsurgical clipping, which may affect the long-term stability and rates of rebleeding. ${ }^{8-11}$

The results of ISAT were based on a selected patient population suitable for both endovascular and surgical treatment in a trial setting. Little data are available on the outcome of patients who are either endovascularly or surgically treated in a routine clinical practice. In our center, intracranial aneurysms are treated either by surgical or by endovascular means, according to a decision reached by a multidisciplinary team that includes a neurologist, neurosurgeon, and interventional radiologist. Therefore, the purpose of the present study was to review the outcome of a consecutive cohort of patients who were either endovascularly or surgically treated for a ruptured intracranial aneurysm in a routine clinical setting. The outcome was determined by rates of survival, independence, retreatment, and rebleeding after $\geq 1$ year of clinical follow-up.

\section{Materials and Methods}

\section{Patients}

Between 2000 and 2008, 531 consecutive patients harboring $\geq 1$ intracranial aneurysm were admitted to our institution. We retrospec- 


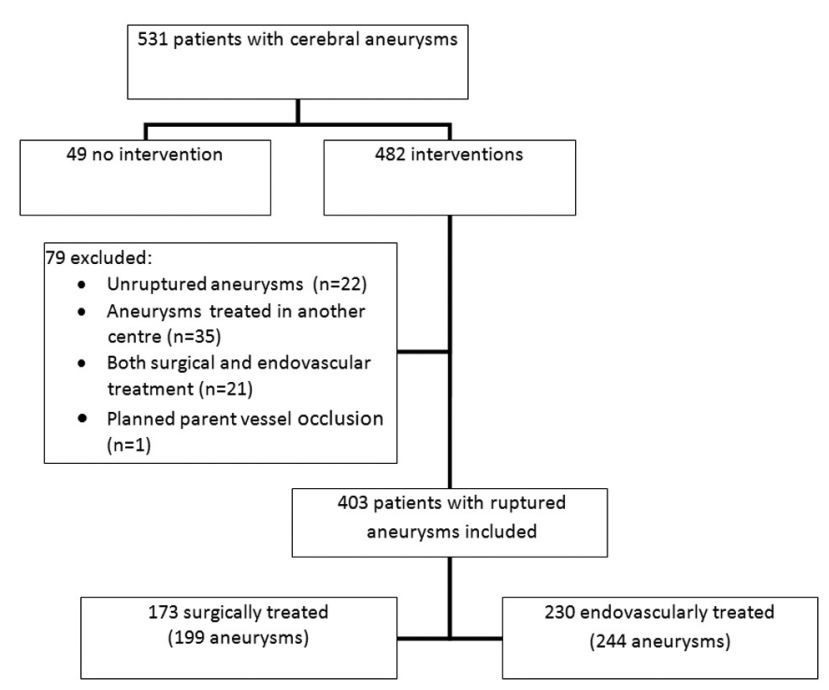

Fig 1. Flow diagram of patient selection.

tively reviewed the medical reports, imaging studies, and reports of endovascular and surgical procedures of these patients.

$\mathrm{SAH}$ was diagnosed by cerebral CT or CSF examination. The aneurysmal origin of the SAH was confirmed by CTA, MRA, or DSA. The clinical status of the patient was rated by using the $\mathrm{HH} .{ }^{12}$ All patients received calcium channel blockers.

Figure 1 shows the flow diagram of our patient selection. Patients were included in our analysis if they had a ruptured intracranial aneurysm and underwent either surgical or endovascular treatment. Patients were excluded from this analysis if they met any of the following criteria: 1) presenting with no ruptured intracranial aneurysm, 2) $\geq 1$ aneurysm treated in another center, 3) both surgical and endovascular treatment applied in 1 patient, and 4) aneurysms treated by parent vessel occlusion. One hundred twenty-eight patients were excluded from the analysis: Forty-nine patients did not receive an intervention, and 79 were treated but did not meet the inclusion criteria (Fig 1). The remaining 403 patients presenting with a ruptured aneurysm were included in this study.

\section{Treatment Protocol}

Patient selection for either endovascular coiling or surgical clipping was made by a multidisciplinary team, including a neurologist, neurosurgeon, and interventional radiologist. Endovascular coiling was the preferential treatment for all patients admitted to our institution; surgery was limited to those cases not suitable for coiling. Patients presenting with $\mathrm{HH} 4-5$ following a ruptured aneurysm were not eligible for surgical treatment. However, in case of an emergency craniotomy for intracranial decompression in this group of patients, surgical clipping could also be performed. HH 4 or 5 was usually not considered to be a contraindication for endovascular treatment.

Endovascular treatment was performed by an interventional neuroradiologist, with the patient under general anesthesia. We used mainly GDCs (Boston Scientific, Natick, Massachusetts). Use of the balloon-assisted technique or TriSpan coils (Boston Scientific) was restricted to patients with aneurysms that were not suitable for neurosurgical treatment and when the aneurysm could not be coiled successfully without these additional devices.

Coil placement was continued until complete angiographic obliteration was achieved or no more coils could be placed safely in the aneurysm. All patients received 5000 IU heparin during the proce-

\begin{tabular}{lcc}
\hline \multicolumn{3}{l}{ Table 1: Patient and aneurysm characteristics } \\
\hline & $\begin{array}{c}\text { Surgical Group } \\
\text { (No.) (\%) }\end{array}$ & $\begin{array}{c}\text { Endovascular } \\
\text { Group (No.) (\%) }\end{array}$ \\
\hline No. of patients & $173(42.9)$ & $230(57.1)$ \\
Male/female & $52(30.1) / 121(69.9)$ & $68(29.6) / 162(70.4)$ \\
Age (yr) (mean) & $17-77(53.1)$ & $16-97(53.6)$ \\
No. of aneurysms treated & 199 & 244 \\
No. of aneurysms treated & & \\
$\quad$ per patient & & \\
1 & $153(88.4)$ & $218(94.8)$ \\
2 & $16(9.2)$ & $10(4.3)$ \\
3 & $3(1.7)$ & $2(0.9)$ \\
5 & $1(0.6)$ & - \\
Size of treated aneurysm & & \\
Small (<5 mm) & $96(48.2)$ & $98(40.2)$ \\
Medium (5-15 mm) & $90(45.2)$ & $136(55.7)$ \\
Large (15-25 mm) & $13(6.5)$ & $10(4.1)$ \\
Aneurysm morphology & & \\
Saccular & $198(99.5)$ & $242(99.2)$ \\
Dissecting & - & $1(0.4)$ \\
Fusiform & $1(0.5)$ & $1(0.4)$ \\
\hline
\end{tabular}

dure. Postoperative patients were treated with a therapeutic dose of low-molecular-weight heparin for 2 days. Thereafter, patients were prescribed antiplatelet therapy.

Surgical treatment was performed by a neurosurgeon and consisted of direct clipping of the aneurysm neck. Wrapping and coagulation of the aneurysm were performed if the aneurysm neck was not suitable for clipping. Temporary clipping of the parent artery was performed at the discretion of the surgeon. Flow measurements were performed if possible.

\section{Series}

Four hundred three patients harboring 443 treated aneurysms were included in this study; 173 patients harboring 199 treated aneurysms underwent surgical treatment. Clipping was performed in 190 aneurysms, 2 of which had additional wrapping; 9 underwent primary coagulation and wrapping without clips being placed. Two hundred thirty patients harboring 244 aneurysms underwent endovascular treatment; the balloon-assisted technique was used in only 4 aneurysms, and the TriSpan coil, in 1 aneurysm.

Table 1 shows the patient and aneurysm characteristics. The distribution of age, sex, number of aneurysms treated, size, and morphology was very similar in both groups. Aneurysm locations are given in Table 2. The MCA was the only location in which more cases were treated by surgery than by endovascular techniques. This was mainly because of the anatomic characteristics of these aneurysms, which often have wide necks and incorporation of MCA branches. Aneurysms of the posterior circulation, however, were treated more frequently by endovascular coiling than by surgery.

Regarding the mean clinical grading specified in Table 3, the clinical condition before treatment in the surgical group was significantly better than that in the group undergoing endovascular treatment $(P=.018)$.

\section{Follow-Up}

Clinical follow-up was performed in the endovascular and surgical groups during outpatient clinic visits. The report of the outpatient visits was missing in 43 patients. In those patients, the clinical follow-up was obtained by structured telephone interviews and by information provided by the general practitioner. Patients with a clini- 


\begin{tabular}{|c|c|c|}
\hline Location & $\begin{array}{c}\text { Surgical } \\
\text { Group (No.) } \\
(\%)\end{array}$ & $\begin{array}{c}\text { Endovascular } \\
\text { Group (No.) } \\
(\%)\end{array}$ \\
\hline$\overline{I C A}$ & $27(13.6)$ & $69(28.3)$ \\
\hline Cavernous & - & 2 \\
\hline Ophthalmic & - & 4 \\
\hline PcomA & 20 & 54 \\
\hline Anterior choroidal artery & 3 & - \\
\hline Bifurcation & 4 & 9 \\
\hline ACA & 79 (39.7) & $110(45.1)$ \\
\hline $\mathrm{A} 1$ & 5 & 1 \\
\hline AcomA & 66 & 102 \\
\hline $\mathrm{A} 2$ & 8 & 7 \\
\hline MCA & 89 (46.1) & $24(9.8)$ \\
\hline Proximal (M1) & 19 & 3 \\
\hline Bifurcation & 62 & 19 \\
\hline M2 & 5 & 2 \\
\hline Posterior circulation & $7(3.6)$ & $41(16.8)$ \\
\hline Vertebral artery & - & 1 \\
\hline Basilar artery junction & - & 27 \\
\hline SCA & - & 3 \\
\hline PCA & 1 & 2 \\
\hline PICA & 6 & 8 \\
\hline Total & $199(100)$ & $244(100)$ \\
\hline
\end{tabular}

\begin{tabular}{lcc}
\hline \multicolumn{3}{l}{ Table 3: Clinical grading at presentation } \\
\hline HH & $\begin{array}{c}\text { Surgical Group (No.) } \\
(\%)\end{array}$ & $\begin{array}{c}\text { Endovascular Group (No.) } \\
(\%)\end{array}$ \\
\hline 1 & $64(37.0)$ & $65(28.2)$ \\
2 & $56(32.4)$ & $65(28.2)$ \\
3 & $17(9.8)$ & $42(18.3)$ \\
4 & $23(13.3)$ & $29(12.6)$ \\
5 & $13(7.5)$ & $29(12.6)$ \\
Total & 173 & 230 \\
\hline
\end{tabular}

cal follow-up period of $<1$ year were considered to be lost to followup. The clinical outcome was determined according to the following mRS criteria ${ }^{13}: 0=$ no symptoms; $1=$ no significant disability, despite symptoms; $2=$ slight disability; $3=$ moderate disability; $4=$ moderately severe disability; $5=$ severe disability; and $6=$ death. Clinically suspected rebleeding was confirmed by a CT scan of the brain.

Angiographic postprocedural follow-up was performed by using DSA. The completeness of aneurysm occlusion was assessed by using the Raymond classification (complete aneurysm occlusion, residual neck, or residual aneurysm). ${ }^{14}$ In the endovascular treatment group, a postprocedural angiogram was always obtained at the end of the coiling procedure. Imaging follow-up of coiled aneurysms was routinely performed at 6 and 24 months after treatment. In case of increasing coil compaction, angiographic follow-up was performed more frequently. Imaging follow-up was performed by DSA (62.4\%) and MRA (37.6\%).

Imaging follow-up after neurosurgery was not standard practice but was performed if the neurosurgeon found it necessary. This follow-up was performed by DSA (63.2\%), MRA (10.5\%), or CTA (26.3\%).

In case of coil compaction, the problem was discussed by a multidisciplinary team. An increasing size of the aneurysm remnant was only retreated if retreatment was considered necessary and safe by the multidisciplinary team.

\begin{tabular}{|c|c|c|}
\hline & $\begin{array}{c}\text { Surgical Group (No.) } \\
(\%)\end{array}$ & $\begin{array}{c}\text { Endovascular Group (No.) } \\
(\%)\end{array}$ \\
\hline \multicolumn{3}{|l|}{$\overline{\mathrm{mRS}}$} \\
\hline 0 & $39(25.7)$ & $53(28.3)$ \\
\hline 1 & $34(22.4)$ & $52(27.8)$ \\
\hline 2 & $49(32.2)$ & $58(31.0)$ \\
\hline 3 & $17(11.2)$ & $10(5.3)$ \\
\hline 4 & $9(5.9)$ & $7(3.7)$ \\
\hline 5 & $4(2.6)$ & $7(3.7)$ \\
\hline Total & 152 & 187 \\
\hline
\end{tabular}

\section{Statistics}

Continuous variables are presented with means and ranges. Categoric data are given as frequencies and percentages and analyzed by $t$ test, Fisher exact test, or $\chi^{2}$ test, accordingly. A $P$ value $<.05$ was considered to be statistically significant.

\section{Results}

\section{Clinical}

During the follow-up period, 20 patients $(11.6 \%)$ died after surgical treatment, $10(50 \%)$ of whom were graded $\mathrm{HH} 4$ or 5 at the time of presentation. Of these 20 deaths, 17 were related to the SAH or treatment of the intracranial aneurysm. The other 3 patients died of a pancreatic carcinoma $(n=1)$ or myocardial infarction $(n=2)$. In the endovascular group, 40 patients $(17.4 \%)$ had died at the end of the follow-up period, 26 of whom $(65 \%)$ were graded 4 or 5 on the $\mathrm{HH}$ at the time of presentation. Thirty-eight deaths were related to the SAH or the coiling of the intracranial aneurysm. One patient died of a lung carcinoma, and 1 died after cardiac failure. Of these 38 deaths, 10 patients developed vasospasm during the procedure, 6 patients had a thromboembolic complication during the procedure, and 5 patients died after rebleeding. In the other 17 patients, no complications occurred, and they died of a serious preprocedural clinical condition.

Clinical follow-up (mean, 33.9 months; range, 12-106 months) was completed in 339 of the 343 surviving patients (98.9\%). Follow-up information was missing for 1 and 3 patients in the surgical and endovascular groups, respectively. Three patients were foreigners visiting the Netherlands at the time of $\mathrm{SAH}$, and 1 patient moved away. The clinical outcome of the surviving patients as expressed by the $\mathrm{mRS}$ is shown in Table 4 . In the surgical and endovascular groups respectively, $122(80.3 \%)$ and $163(87.2 \%)$ patients were able to live independently (mRS 0-2).

More patients died after endovascular treatment $(P=$ $.104)$, and fewer people were able to live independently after surgical treatment $(P=.084)$. However these differences were not statistically significant.

\section{Imaging}

Table 5 shows the findings of postprocedural imaging. In the surgical group, follow-up imaging was performed in 126 $(63.3 \%)$ aneurysms; most of these were within a year after surgery $(88.9 \%)$. Imaging showed complete occlusion in 101 $(80.2 \%)$ aneurysms after surgical treatment, a residual neck in $17(13.5 \%)$, and a residual aneurysm in $8(6.3 \%)$ aneurysms. All aneurysms treated by endovascular therapy underwent 


\begin{tabular}{lcc}
\hline & $\begin{array}{c}\text { Surgical } \\
\text { Group }(n=199) \text { (No.) } \\
(\%)\end{array}$ & $\begin{array}{c}\text { Endovascular Group }(n=244)(\text { No.) } \\
(\%)\end{array}$ \\
\hline No. of aneurysms with imaging & $126(63.3)$ & $244(100)$ \\
Complete occlusion & $101(80.2)$ & $149(61.1)$ \\
Residual neck & $17(13.5)$ & $60(24.6)$ \\
Residual aneurysms & $8(6.3)$ & $35(14.3)$ \\
No. of aneurysms without imaging & $73(36.7)$ & $0(0)$ \\
\hline
\end{tabular}

postprocedural imaging at the end of the procedure. In 149 $(61.1 \%)$ of these aneurysms, complete occlusion was demonstrated, in $60(24.6 \%)$ a residual neck, and in $35(14.3 \%)$ a residual aneurysm. Complete aneurysm occlusion occurred significantly more often after surgical treatment compared with endovascular treatment $(P<.001)$.

Late imaging follow-up was available for a group of 38 surgically treated patients ( $24.8 \%$ of those surviving) harboring 50 aneurysms. The average interval between treatment and the last imaging was 35.5 months (range, 10.3-105.5 months). Aneurysm regrowth was observed in 6 aneurysms (12.0\%) after surgical treatment. Three of these aneurysms had demonstrated a known residual aneurysm at an earlier post-operative imaging. Four of these aneurysms were primary or additionally treated by coagulation or wrapping. Retreatment was performed in 4 of 199 (2.0\%) aneurysms, in all cases after rebleeding. Because only a small group of surgically treated patients underwent follow-up angiography, no further results were obtained from this follow-up.

Table 6 shows the findings at follow-up imaging in aneurysms that had undergone endovascular treatment. This was available for 181 surviving patients (95.3\%, harboring 189 aneurysms). The average interval between treatment and the last follow-up was 29.1 months (range, 4.8-102.8 months). Increasing compaction was observed in 72 aneurysms (38.1\%); this occurred more often in the group that showed a residual aneurysm at the end of the procedure $(52.0 \%)$ than in those with complete occlusion $(36.8 \%)$ or a residual neck $(34.0 \%)$ determined at postprocedural angiography. However, this difference was not statistically significant $(P=.124)$.

Retreatment was performed in 16 aneurysms in the endovascular group, 2 after rebleeding and 14 without rebleeding. At the end of the first procedure, 10 of these showed a residual aneurysm, 4 aneurysms had a residual neck, and 2 were completely occluded after coiling.

\section{Rebleeds}

After the procedure, rebleeding from the target aneurysm occurred in 12 aneurysms: Six (2.5\%) occurred after endovascular treatment, and $6(3.0 \%)$, after surgical treatment. This difference was not statistically significant $(P=.769)$.
Four patients of the endovascular treatment group had a residual aneurysm shown by postprocedural imaging, and 2 had a residual neck. In the endovascular group, the presence of a residual neck after coiling was not related to rebleeding $(P=$ $.085)$. The presence of a residual aneurysm after coiling was statistically significantly related to rebleeding $(P=.001)$.

One of the surgically treated patients mentioned above had a residual aneurysm; the other 5 did not undergo postprocedural imaging. Because of the missing data, no analysis could be performed on the surgically treated aneurysms. Outcome of rebleeds was poor (Table 7).

\section{Discussion}

The primary goal of aneurysm treatment is to prevent aneurysm bleeding or rebleeding and thereby decrease the risk of death and dependency. This study presents the results of both types of treatment of intracranial aneurysms in symptomatic patients in a routine clinical setting.

After a median follow-up period of 33.9 months, $11.6 \%$ of the surgically treated and $17.4 \%$ of the endovascularly treated patients had died. ISAT reported different mortality rates after a follow-up period of 5 years: $11 \%$ after coiling and 14\% after surgical treatment. ${ }^{5}$ These differences can be explained by the inclusion criteria and the clinical status at presentation. In our study, all patients presenting with an intracranial aneurysm were analyzed. In the group undergoing endovascular treatment, only $56.4 \%$ had a good clinical grading at presentation (HH 1-2); in the surgically treated patients, this was $69.4 \%$. ISAT included only patients whose clinical condition was suitable for both coiling and surgical clipping. A clinical grading of HH $1-2$ at presentation was seen in $88 \%$ of these patients. ${ }^{3-5}$

At the end of the follow-up period, $80.3 \%$ and $87.2 \%$ of the surviving patients in the surgical and endovascular group respectively were living independently (mRS $1-2)$. These results are comparable with the ISAT study, which describes a good clinical outcome (mRS $1-2$ ) in $82 \%$ and $83 \%$ of the surviving patients after surgery and coiling respectively. ${ }^{5}$

The overall risk of rebleeding tends to be greater after coiling compared with surgical clipping. ${ }^{4,5,15}$ In ISAT and other published studies, rebleeding rates after surgical treatment varied from $1.1 \%$ to $3.2 \%$, while after endovascular treatment,

\begin{tabular}{|c|c|c|c|}
\hline & $\begin{array}{l}\text { No Changes (No.) } \\
(\%)\end{array}$ & $\begin{array}{c}\text { Improvement (No.) } \\
(\%)\end{array}$ & $\begin{array}{c}\text { Increased Recanalization (No). } \\
(\%)\end{array}$ \\
\hline \multicolumn{4}{|l|}{ Results of postprocedural imaging } \\
\hline Complete occlusion ( $n=114$ ) & $72(63.2)$ & - & $42(36.8)$ \\
\hline Residual neck $(n=50)$ & $24(48.0)$ & $9(18.0)$ & $17(34.0)$ \\
\hline Residual aneurysm $(n=25)$ & $12(48.0)$ & - & $13(52.0)$ \\
\hline Total 189 & $108(57.1)$ & $9(4.8)$ & $72(38.1)$ \\
\hline
\end{tabular}




\begin{tabular}{|c|c|c|c|c|c|c|c|}
\hline $\begin{array}{l}\text { Age/ } \\
\text { Sex }\end{array}$ & Location & $\begin{array}{l}\text { Size } \\
(\mathrm{mm})\end{array}$ & $\begin{array}{c}\text { Initial } \\
\text { Intervention }\end{array}$ & $\begin{array}{l}\text { Postprocedural Imaging } \\
\text { Results }\end{array}$ & $\begin{array}{l}\text { Time to Rebleed } \\
\text { (days) }\end{array}$ & Intervention & $\mathrm{mRS}$ \\
\hline$\overline{48 / F}$ & MCA bifurcation & 8 & Coiling & Residual aneurysm & 1 & None & 6 \\
\hline $56 / F$ & AcomA & 7 & Coiling & Residual neck & 2 & None & 6 \\
\hline $63 / \mathrm{M}$ & AcomA & 2 & Coiling & Residual aneurysm & 1562 & None & 6 \\
\hline $49 / F$ & MCA M2 & 2 & v & Residual neck & 43 & None & 6 \\
\hline $48 / F$ & AcomA & 4 & Coiling & Residual aneurysm & 83 & Recoiling & 4 \\
\hline $70 / F$ & AcomA & 10 & Coiling & Residual aneurysm & 3373 & Recoiling & 6 \\
\hline $44 / F$ & AcomA & 3 & Coagulation & Aneurysm regrowth & 1396 & Reclipping & 2 \\
\hline $40 / F$ & PcomA & 5 & Clipping & $?^{\mathrm{a}}$ & 1 & None & 6 \\
\hline $65 / M$ & AcomA & 5 & Clipping & Clip slipped ${ }^{\mathrm{b}}$ & 57 & Coiling & 2 \\
\hline $40 / F$ & AcomA & 15 & Clipping & $?^{a}$ & 2 & None & 6 \\
\hline $47 / M$ & MCA bifurcation & 6 & Clipping & Residual aneurysm & 507 & Coiling & 3 \\
\hline $49 / F$ & AcomA & 4 & Clipping & Clip slipped ${ }^{\mathrm{b}}$ & 12 & Reclipping & 0 \\
\hline
\end{tabular}

a Indicates no postprocedural imaging was performed.

${ }^{\mathrm{b}}$ Clip that slipped from the aneurysm became clear at angiography after rebleed.

the rates varied from $2.1 \%$ to $3.5 \%$, depending on the occlusion rates and on the follow-up period. ${ }^{4,5,15-22}$ In the present study, rebleeding occurred with approximately equal frequency after surgery compared with endovascular treatment, $3.0 \%$ and $2.5 \%$ respectively. Coiling is known to result in lower rates of complete occlusion compared with microsurgical clipping, which may affect the long-term stability and rates of rebleeding. ${ }^{8-11}$ In the present study, a residual aneurysm was seen at postprocedural imaging in $14.2 \%$ of the patients having undergone endovascular treatment and in $4.3 \%$ of those treated by surgery. This group of neurosurgically treated aneurysms probably forms a selected population because posttreatment imaging was not standard procedure in the first years of inclusion. In case of doubt as to whether the aneurysm had been occluded satisfactorily or in patients with multiple aneurysms when $\geq 1$ aneurysm had remained untreated, postclipping imaging was more likely to have been performed. Even in this selected population, complete aneurysm occlusion occurred significantly more often after surgical treatment compared with endovascular treatment $(P<.001)$.

Progressive coil compaction after endovascular treatment was seen more often when a residual aneurysm was present at postprocedural imaging compared with completely occluded aneurysms and residual necks at postprocedural imaging; however, this difference was not statistically significant $(P=$ $.35)$. The presence of a residual aneurysm was statistically significantly related to rebleeding $(P=.007)$. These results are supported by other studies. The Cerebral Aneurysm Rerupture After Treatment study found the degree of aneurysm occlusion to be highly predictive of the risk for rerupture. ${ }^{15} \mathrm{Wil}-$ linsky et $\mathrm{al}^{16}$ found significantly more frequent recanalization in patients with a residual aneurysm, though the rebleeding rates did not show a difference for completely occluded aneurysms or for aneurysms with a neck or residual aneurysm.

\section{Study Limitations}

The primary goal of the present study was to assess how patient outcome in routine clinical practice relates to those reported in the literature. However, our study was not a randomized trial; therefore, a direct comparison of outcomes of between endovascular and surgical treatment is not strictly valid.

The number of patients presenting in our center with an
SAH from a ruptured aneurysm was relatively small but has grown in the past few years.

The clinical loss to follow-up in our study was very low (1.1\%). However, in 43 patients, the clinical follow-up was obtained from structured telephone interviews and by information provided by the general practitioner. This may make the clinical outcome graded by the mRS less reliable.

Postprocedural imaging was available for all patients after endovascular treatment. However postprocedural imaging after surgery was only available for $64.8 \%$ of the patients.

The use of balloon or TriSpan coils in our clinic was low. This treatment was restricted to patients with aneurysms that were not suitable for neurosurgical treatment and when the aneurysm could not be treated endovascularly without these additional devices. We think that the risk of complications in most cases in which an additional device is needed for endovascular treatment is higher than the risk of neurosurgical clipping, while the outcome in the long term is nearly the same. $^{23,24}$

\section{Conclusions}

The management of patients with intracranial aneurysms by endovascular or surgical treatment in a routine clinical setting according to a decision reached by a multidisciplinary team confirms the efficacy of such a policy. Mortality rates are comparable with those in the literature when the frequently poor clinical condition of patients at the time of presentation is taken into account. Furthermore, the rates of dependency are low in both treatment groups. Coiling results in lower rates of complete aneurysm occlusion compared with surgical treatment. Postcoiling angiography showing a residual aneurysm is a good predictor of the risk of rebleeding.

\section{References}

1. Rinkel GJ, Djibuti M, Algra A, et al. Prevalence and risk of rupture of intracranial aneurysms: a systematic review. Stroke 1998;29:251-56

2. Guglielmi G, Viñuela F, Sepetka I, et al. Electrothrombosis of saccular aneurysms via endovascular approach. Part 1. Electrochemical basis, technique, and experimental results. J Neurosurg 1991;75:1-7

3. Guglielmi G, Viñuela F, Dion J, et al. Electrothrombosis of saccular aneurysms via endovascular approach. Part 2: Preliminary clinical experience. J Neurosurg 1991;75:8-14

4. Molyneux A, Kerr R, Stratton I, et al. International Subarachnoid Aneurysm Trial (ISAT) of neurosurgical clipping versus endovascular coiling in 2143 
patients with ruptured intracranial aneurysms: a randomised trial. Lancet 2002;360:1267-74

5. Molyneux AJ, Kerr RS, Yu LM, et al. International Subarachnoid Aneurysm Trial (ISAT) of neurosurgical clipping versus endovascular coiling in 2143 patients with ruptured intracranial aneurysms: a randomised comparison of effects on survival, dependency, seizures, rebleeding, subgroups, and aneurysm occlusion. Lancet 2005;366:809-17

6. Molyneux AJ, Kerr RS, Birks J, et al. Risk of recurrent subarachnoid haemorrhage, death, or dependence and standardised mortality ratios after clipping or coiling of an intracranial aneurysm in the International Subarachnoid Aneurysm Trial (ISAT): long-term follow-up. Lancet Neurol 2009;8:427-33. Epub 2009 Mar 28

7. Raja PV, Huang J, Germanwala AV, et al. Microsurgical clipping and endovascular coiling of intracranial aneurysms: a critical review of the literature. $\mathrm{Neu}$ rosurgery 2008;62:1187-202, discussion 1202-03

8. Raymond J, Guilbert F, Weill A, et al. Long-term angiographic recurrences after selective endovascular treatment of aneurysms with detachable coils. Stroke 2003;34:1398-403. Epub 2003 May 29

9. Grunwald IQ, Papanagiotou P, Struffert T, et al. Recanalization after endovascular treatment of intracerebral aneurysms. Neuroradiology 2007;49:41-47. Epub 2006 Nov 9

10. Holmin S, Krings T, Ozanne A, et al. Intradural saccular aneurysms treated by Guglielmi detachable bare coils at a single institution between 1993 and 2005: clinical long-term follow-up for a total of $\mathbf{1 8 1 0}$ patient-years in relation to morphological treatment results. Stroke 2008;39:2288-97. Epub 2008 Jun 26

11. Lot G, Houdart E, Cophignon J, et al. Combined management of intracranial aneurysms by surgical and endovascular treatment: modalities and results from a series of 395 cases. Acta Neurochir (Wien) 1999;141:557-62

12. Hunt WE, Hess RM. Surgical risk as related to time of intervention in the repair of intracranial aneurysms. J Neurosurg 1968;28:14-20

13. Kasner SE. Clinical interpretation and use of stroke scales. Lancet Neurol 2006;5:603-12
14. Roy D, Milot G, Raymond J. Endovascular treatment of unruptured aneurysms. Stroke 2001;32:1998-2004

15. Johnston SC, Dowd CF, Higashida RT, et al. Predictors of rehemorrhage after treatment of ruptured intracranial aneurysms: the Cerebral Aneurysm Rerupture After Treatment (CARAT) study. Stroke 2008;39:20-05. Epub 2007 Nov 29

16. Willinsky RA, Peltz J, da Costa L, et al. Clinical and angiographic follow-up of ruptured intracranial aneurysms treated with endovascular embolization. AJNR Am J Neuroradiol 2009;30:1035-40. Epub 2009 Mar 19

17. Aikawa H, Kazekawa K, Nagata S, et al. Rebleeding after endovascular embolization of ruptured cerebral aneurysms. Neurol Med Chir (Tokyo) 2007;47: 439-45, discussion 446-47

18. Sluzewski M, van Rooij WJ. Early rebleeding after coiling of ruptured cerebral aneurysms: incidence, morbidity, and risk factors. AJNR Am J Neuroradio 2005; $26: 1739-43$

19. Sluzewski M, van Rooij WJ, Beute GN, et al. Late rebleeding of ruptured intracranial aneurysms treated with detachable coils. AJNR Am J Neuroradiol 2005;26:2542-49

20. Tsutsumi K, Ueki K, Usui M, et al. Risk of recurrent subarachnoid hemorrhage after complete obliteration of cerebral aneurysms. Stroke 1998;29:2511-13

21. Wermer MJ, Greebe P, Algra A, et al. Incidence of recurrent subarachnoid hemorrhage after clipping for ruptured intracranial aneurysms. Stroke 2005 36:2394-99. Epub 2005 Oct 6

22. David CA, Vishteh AG, Spetzler RF, et al. Late angiographic follow-up review of surgically treated aneurysms. J Neurosurg 1999;91:396-401

23. Sluzewski M, van Rooij WJ, Beute GN, et al. Balloon-assisted coil embolization of intracranial aneurysms: incidence, complications, and angiography results. J Neurosurg 2006;105:396-99

24. Piotin M, Blanc R, Spelle L, et al. Stent-assisted coiling of intracranial aneurysms: clinical and angiograhic results in 216 consecutive aneurysms Stroke 2010;41:110-05. Epub 2009 Dec 3 